\title{
Building geopolymers for CuHe part l: thermal properties of raw materials as precursors for geopolymers
}

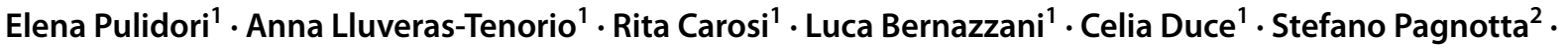 \\ Marco Lezzerini $^{2}$ - Germana Barone ${ }^{3}$. Paolo Mazzoleni ${ }^{3} \cdot$ Maria Rosaria Tiné $^{1}$ (D)
}

Received: 31 May 2021 / Accepted: 11 September 2021 / Published online: 25 October 2021

(c) The Author(s) 2021

\begin{abstract}
This paper presents the results obtained from the thermal analysis of a set of geomaterials (clays, pyroclastic materials, and industrial recycled materials) to be used as raw materials for the synthesis of geopolymers, specifically designed for the conservation of Cultural Heritage $(\mathrm{CH})$ buildings, particularly in seismic hazard zones such as Sicily. X-ray diffraction and gas volumetric analysis (calcimetry) were applied to this set of raw materials in order to characterize the materials from the chemical and structural point of view. Thermogravimetric analysis (TG), TG coupled to Fourier transform infrared spectroscopy (TG-FTIR), and differential scanning calorimetry were used to characterize their thermal behavior. The statistical treatment of the thermogravimetric data by principal component analysis and hierarchical clustering analysis highlights the direct relation between the thermal data and the material composition that will be exploited for the selection of the best materials to obtain geopolymers specifically designed for the conservation of $\mathrm{CH}$ buildings.
\end{abstract}

Keywords Clays · TGA $\cdot$ DSC $\cdot$ Evolved gas analysis $\cdot$ XRD $\cdot$ Clustering

\section{Introduction}

New materials used for Cultural Heritage $(\mathrm{CH})$ conservation purposes should respect the requirements of compatibility with the original materials from a chemical, physical, and mechanical point of view. Furthermore, they should respect the original artwork appearance and esthetics.

In the framework of the project AGM for $\mathrm{CuHe}$ (Advanced Green Materials for Cultural Heritage), geopolymers are being studied as eco-friendly, smart, and with excellent technical characteristics materials for the conservation of historical buildings, monuments, and valuable

Luca Bernazzani

luca.bernazzani@unipi.it

Maria Rosaria Tiné

mariarosaria.tine@unipi.it

1 Department of Chemistry and Industrial Chemistry, University of Pisa, Via G. Moruzzi 13, 56124 Pisa, Italy

2 Department of Earth Sciences, University of Pisa, Via Santa Maria, 53, 56126 Pisa, Italy

3 Department of Biological, Geological and Environmental Science, University of Catania, Corso Italia 57, 95129 Catania, Italy manufactures in areas where the valorization of cultural heritage has great potential as a driving force of the economy.

Geopolymers are inorganic materials produced by activating aluminosilicates with alkali hydroxide or alkali silicate solutions [1]; they present a marked chemical-mineralogical similitude with ceramic bodies and show mechanical, chemical, and thermal properties that seem well suited for their use in the field of $\mathrm{CH}$ intervention.

Geopolymer matrixes have recently been investigated to evaluate their applicability to the restoration and conservation of $\mathrm{CH}$ as repair material in ancient building [2-6], restoration works of historical buildings characterized by reddish façades [7], tiles conservation [8], structural retrofitting of masonry [9], and mortars preparation for different purposes [10-12]. These papers focused their attention on the effect of the use of different alkaline activators, different water/ solid ratios, additives, or of the mechanical activation of the solid precursors on the geopolymer paste. A few papers deal with the preparation and characterization of geopolymers as matrixes for composite materials. For instance, Catauro et al. [13] investigated the behavior of the metakaolin-based geopolymeric matrix incorporating waste glasses, Ricciotti et al. [14] investigated the addition of a limited content of epoxy resin to the geopolymer paste while Tamburini et al. [15] 
tested a system made of geopolymer and fibers on bricks. The peculiar properties of the geopolymers determine their broad application field [16] ranging from coatings to protect reinforced concrete against corrosion [17] to reinforce a sculptural artwork [18] in which the use of a composite obtained by adding a filler to the geopolymer matrix satisfy the restorers demand, i.e., to get close the original porosity, color, and composition of the statue.

The large variability and complexity of masonry structures and typologies, especially when dealing with cultural heritage, makes particularly difficult the preliminary material selection for retrofitting interventions [9]. Moreover, changes in the composition and ratios of the starting raw materials modify the mechanical properties, appearance, and adherence of the geopolymers.

This paper presents the results obtained from the analysis of a wide number of geomaterials (clays, pyroclastic materials, and industrial recycled materials) selected as potential raw materials for the synthesis of geopolymers specifically designed for the conservation of $\mathrm{CH}$ buildings, particularly in seismic hazard zones such as Sicily. The materials have been chosen to allow the design of geopolymer products customized to meet the requirement of different type of substrates, as well environmental and structural conditions, with particular attention to mitigate seismic risk. Furthermore, to reduce production costs, inert and not hazardous industrial wastes, as well volcanic ash currently regarded as waste materials, were considered in the geopolymer design.

Thermogravimetric analysis (TGA) coupled to the evolved gas analysis (EGA) through Fourier transform infrared spectroscopy (FTIR), and differential scanning calorimetry (DSC) have been applied to characterize and semi quantify the characteristic phenomena of dehydration, dehydroxylation and structural decomposition (decarbonatization) occurring, and which are well describe in literature $[19,20]$. A multi-analytical approach including X-ray diffraction (XRD), gas volumetric analysis (calcimetry) has been used to interpret the data related to their mineralogical and chemical composition. The wide set of materials required a statistical analysis of the thermogravimetric data by means of principal component analysis (PCA) and hierarchical clustering analysis (HCA).

\section{Materials and methods}

\section{Materials}

The complete list of the raw materials analyzed, their petrological provenience and some characteristics, are provided in the supplementary material (Table S1). A total of 63 different samples have been analyzed and grouped in four main classes: clays, volcanic rocks, ceramic and building materials. Sand and gravel were also studied for comparison. Clays (45 samples) were additionally classified as Plio-Pleistocene clays (22 samples), Numydian Flysch (17 samples), Sicilide clay (1 sample), and marly clays (5 samples). All materials were sampled in different regions of Sicily (Italy) and are grouped by class, category, and according to the district of their provenience as fully described in Table S1.

\section{Methods}

The thermogravimetric experiments were performed using a TA Instruments Thermobalance model Q5000IR equipped with an FTIR Agilent Technologies spectrophotometer model Cary 640 for evolved gas analysis (EGA). TG-FTIR measurements were performed using Pt crucibles at a rate of $20^{\circ} \mathrm{C} \mathrm{min}^{-1}$, from 30 to $900{ }^{\circ} \mathrm{C}$ under nitrogen flow $(70 \mathrm{~mL}$ $\min ^{-1}$ ). The amount of sample in each measurement varied between 10 and $15 \mathrm{mg}$. Mass calibration was performed using certified mass standards, in the $0-100 \mathrm{mg}$ range, supplied by TA Instruments. The temperature calibration was based on the Curie point of paramagnetic metals. A multipoint calibration with five Curie point reference materials (Alumel, Ni, Ni83\%Co17\%, Ni63\%Co37\%, Ni37\%Co63\%) was performed. TG-FTIR measurements were performed in the range $600-4000 \mathrm{~cm}^{-1}$ with a $4 \mathrm{~cm}^{-1}$ width slit. To reduce the strong background absorption from water and carbon dioxide present in the atmosphere in the TG-FTIR spectra, the optical bench was usually purged with nitrogen. In addition, a background spectrum was taken before the beginning of each analysis in order to zero the signal in the gas cell and to eliminate any contribution from ambient water and carbon dioxide. Spectra of evolved gases were analyzed with the FTIR analysis software KnowItAll@ using the vapor phase databases.

DSC measurements were performed by TA Instruments Discovery DSC model 250 under the nitrogen gas flow $50 \mathrm{~mL} \cdot \mathrm{min}^{-1}$. The DSC was calibrated with Indium. For each sample, 5-6 mg were weighted and put into pin hole aluminum DSC pans. The sample was scanned in the temperature range between $-40-300{ }^{\circ} \mathrm{C}$ with a heating rate of $10{ }^{\circ} \mathrm{C} \min ^{-1}$.

$\mathrm{X}$-ray diffraction analysis was performed by means of a Bruker D2 XRD analyzer, equipped with a $\mathrm{CuK}_{\mathrm{a}}$ radiation $(\mathrm{WL}=0.154 \mathrm{~nm})$, rotation angle $2 \theta=4^{\circ}$ to $66^{\circ}$, and rotation sample of $15 \mathrm{rps}$, in order to obtain a diffraction pattern and the identification of mineralogical phases present in the samples.

Gasometry measurements have been performed using the calcimeter method based on the proposed model in the literature [21] where a reaction chamber connected to a pression gauge that measures the $\mathrm{CO}_{2}$ pression developed by the reaction of $\sim 300 \mathrm{mg}$ of powder with $\mathrm{HCl}$ is used. 
Statistical data treatment by means of principal component analysis (PCA) and hierarchical clustering analysis (HCA) were performed using XLSTAT software by Addinsoft and Orange, a machine learning, and data mining suite for data analysis through Python [22].

(a)
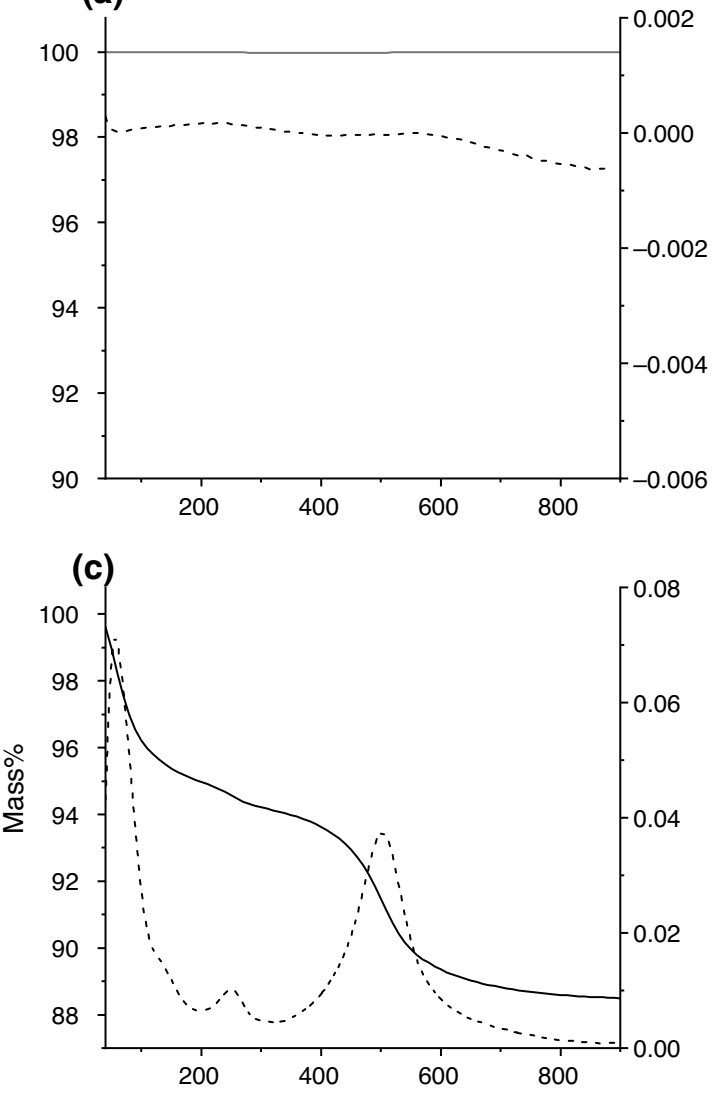

(e)

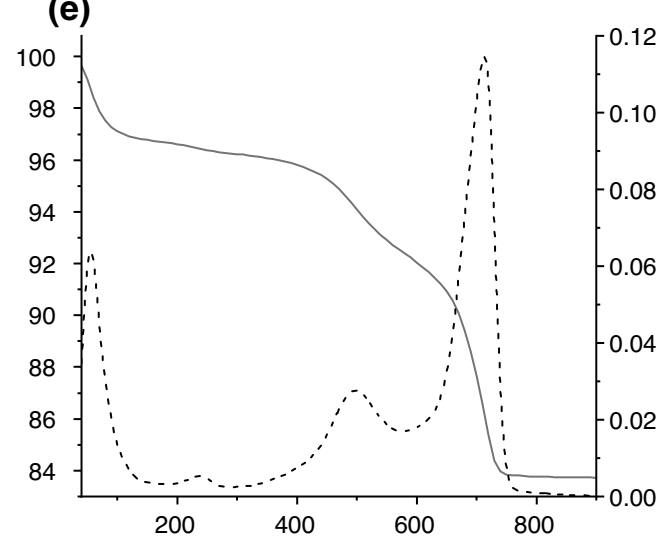

\section{Results}

\section{TG measurements}

Figure 1 shows the thermogravimetric and differential thermogravimetric (DTG) curves of some materials selected as representative of those analyzed. The temperatures of
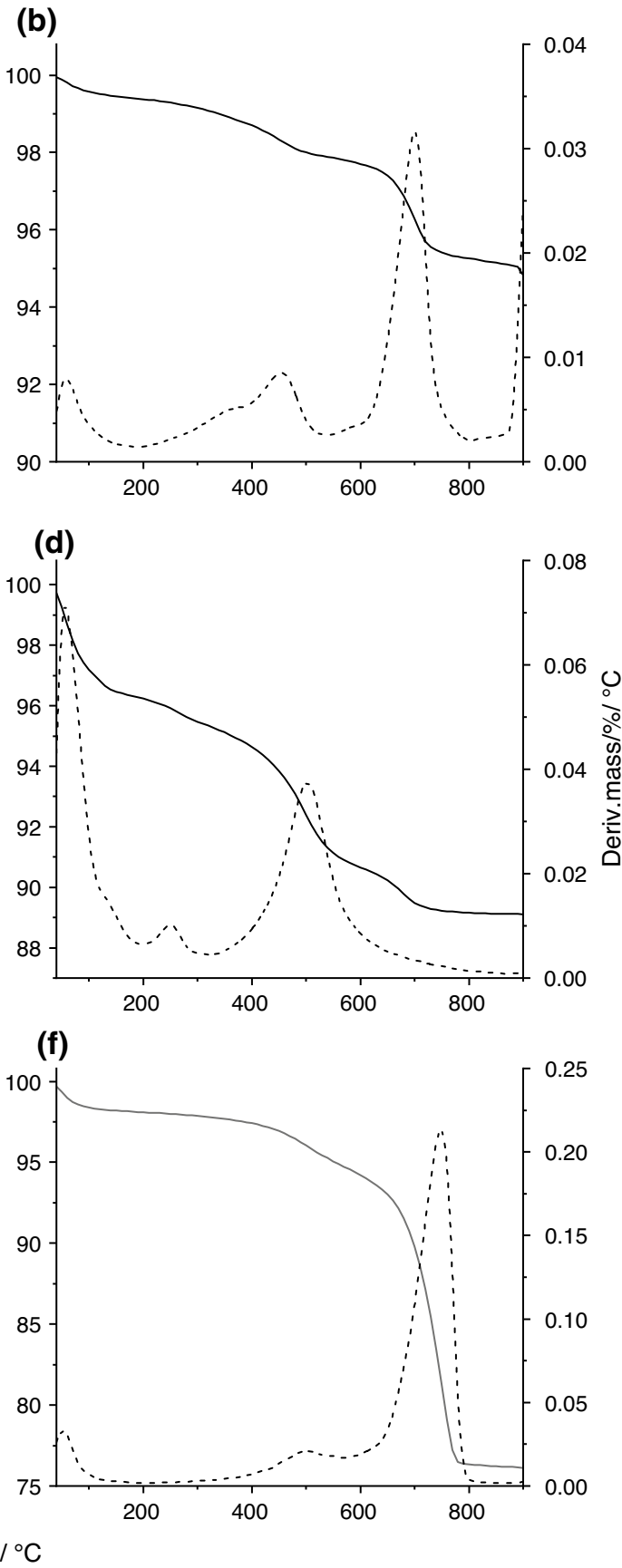

Fig. 1 TG (- ${ }_{-}$and DTG (-- -) curves of samples a SV 2 (crushed basalt); b SM 4 (mixed waste material); c UN3 (Numidian Flysch clay); d USB 11 (Numidian Flysch clay); e LCT 6 (Plio-Pleistocene clay) 
maximum degradation rate, $T_{\max }$, and the corresponding mass loss percentages of the different thermal degradation steps are presented in Tables S2-S3 of SI for the investigated materials grouped according to their class, namely clays (S2), volcanic, building, and ceramic materials (S3). Samples with negligible mass losses were not reported.

We can identify four thermal degradation regions for the overall set of materials considered in this work with a first mass loss in the temperature range $50-150{ }^{\circ} \mathrm{C}$ (step 1), and further mass losses in the range $200-400{ }^{\circ} \mathrm{C}$ (step 2), $400-600{ }^{\circ} \mathrm{C}$ (step 3), and $600-800{ }^{\circ} \mathrm{C}$ (step 4). To identify the chemical phenomena occurring at each degradation step, representative samples of the different classes of materials in the set were analyzed by TGA coupled to FTIR in order to characterize the composition of the gas evolved (EGA) during the thermal treatment of the samples. Figure 2 shows, as an example the TG and DTG curves (a), the intensity of the FTIR signals associated to water $\left(1504 \mathrm{~cm}^{-1}\right)$ and $\mathrm{CO}_{2}\left(2371 \mathrm{~cm}^{-1}\right)$ vs. temperature (b), the FTIR spectra of the gases evolved at $492{ }^{\circ} \mathrm{C}$ (c) and $678{ }^{\circ} \mathrm{C}$ (d) for Cianina (Marly clay).

FTIR spectra exhibit bands associated to $\mathrm{O}-\mathrm{H}$ stretching (4000-3300 $\mathrm{cm}^{-1}$ ) and $\mathrm{H}-\mathrm{O}-\mathrm{H}$ bending $\left(1700-1500 \mathrm{~cm}^{-1}\right)$ and bands attributed to the stretch (doublet at $2350 \mathrm{~cm}^{-1}$ ) and bend $\left(667 \mathrm{~cm}^{-1}\right)$ of $\mathrm{CO}_{2}$ (Fig. 2c, d). The FTIR analysis shows that the species evolved in step 1 and 2 , below $400{ }^{\circ} \mathrm{C}$, is mainly water, while in the step 3 and 4, both water and $\mathrm{CO}_{2}$ are present (Fig. $2 \mathrm{~b}$ ).

In the literature, the thermal analysis of clays allows separating the different steps of water release, that is to distinguish the various types of water present [23]. The water desorbed at temperatures below $100{ }^{\circ} \mathrm{C}$ can be considered water retained in pores or adsorbed on the external surface, while water adsorbed between layers or in structural channels (zeolitic or loosely bound water) is desorbed between 100 and $150^{\circ} \mathrm{C}$. All clays analyzed in this work showed the presence of water in pores and cavities (surface water), as indicated by the main mass loss of step 1 at around $60{ }^{\circ} \mathrm{C}$ (a)

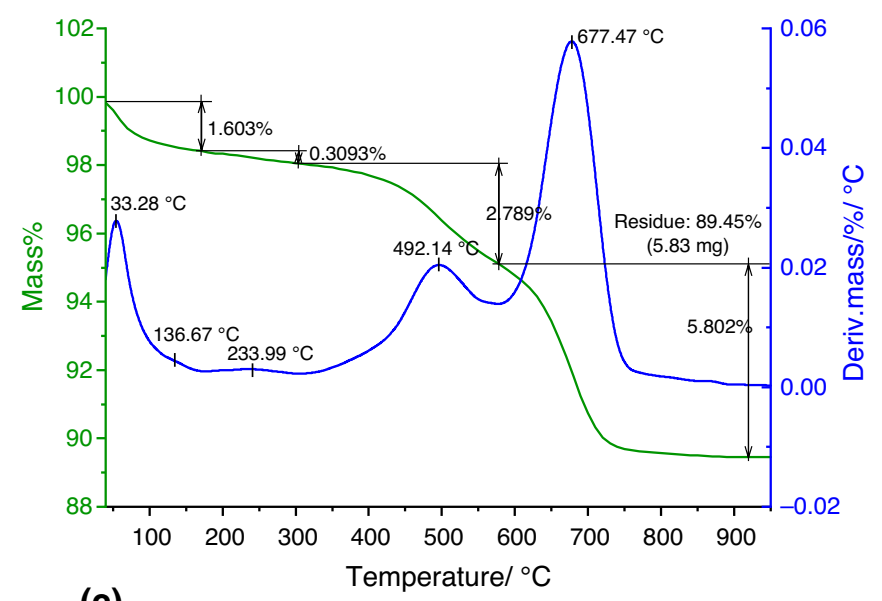

(c)

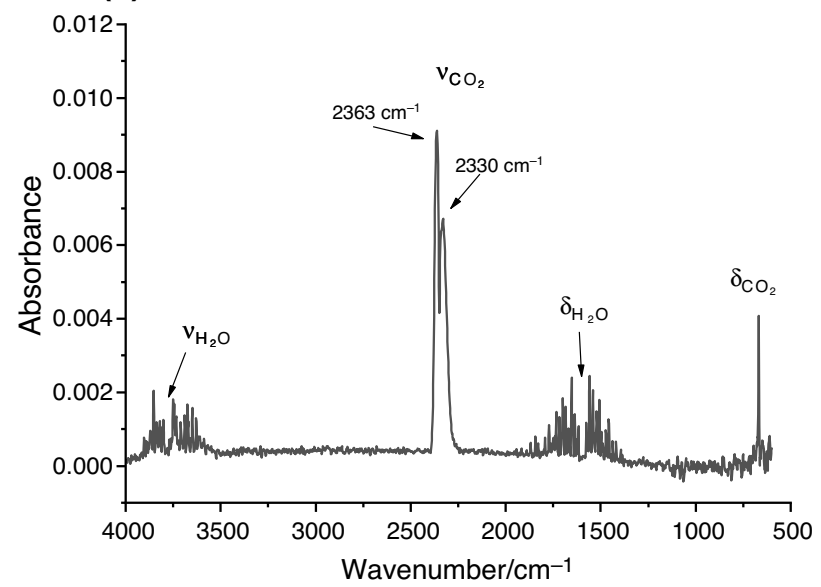

(b)

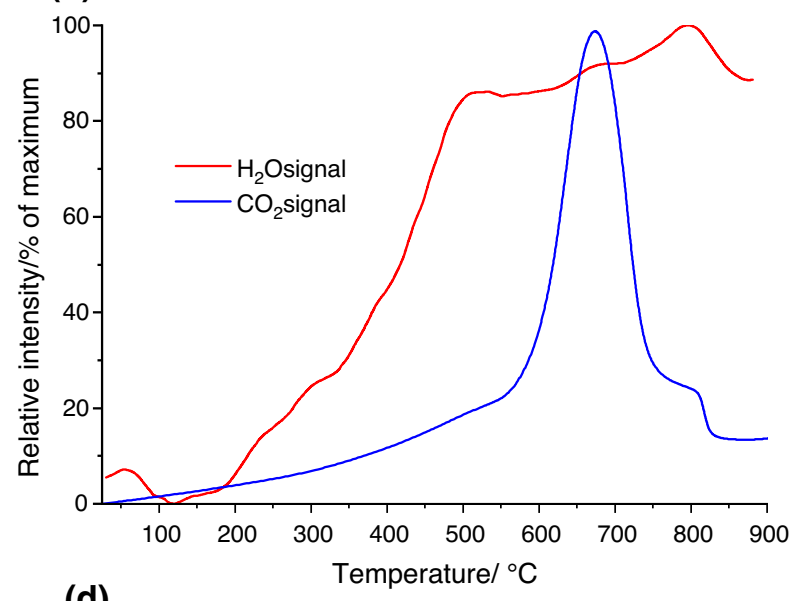

(d)

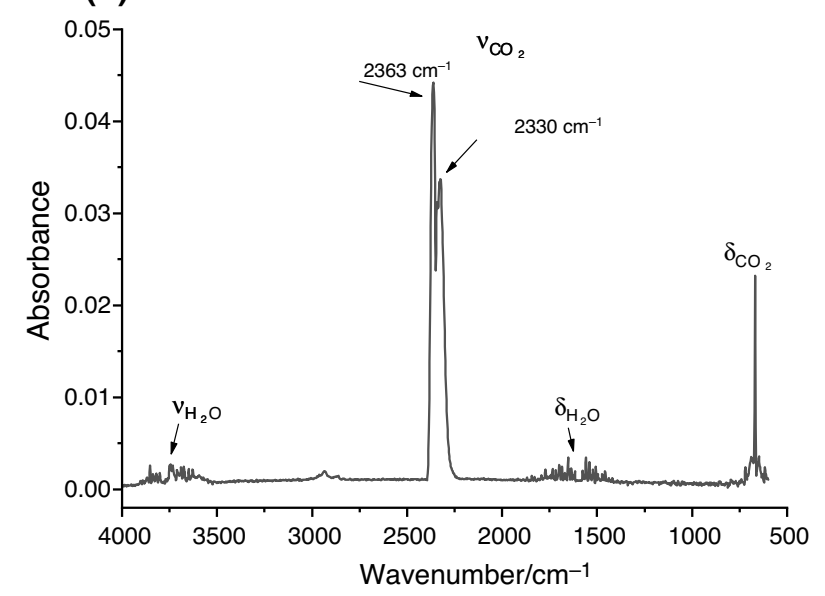

Fig. 2 a TG and DTG curve for sample Cianina (Marly clay); b evolution of $\mathrm{H}_{2} \mathrm{O}$ and $\mathrm{CO}_{2}$ with temperature; c, d FTIR spectra of the evolved gas associated to the mass loss at $T_{\max } 492^{\circ} \mathrm{C}$ and $678^{\circ} \mathrm{C}$, respectively f ENNA (Plio-Pleistocene clay). 
(Table S2). The presence of water adsorbed in the interlayers or structural channels was also assessed for almost all the clays analyzed as $80 \%$ of the samples showed a second peak or a shoulder in the mass loss signal in the range $100-150{ }^{\circ} \mathrm{C}$. A similar behavior is well documented in literature [24-26].

A mass loss in the range $200-400{ }^{\circ} \mathrm{C}$ is present only in about $40 \%$ of the investigated samples and is lower than $1 \%$ for all samples except for SA01, a crushed basalt from Mt. Etna (1.3\%). Where present, the $T_{\text {peak }}$ related to this mass loss falls in a quite narrow temperature range, approximately between 235 and $270{ }^{\circ} \mathrm{C}$ and TG-FTIR experiments show that the mass loss observed in step 2 is mainly related to water elimination. Indeed, many aluminosilicates are known to undergo structural water loss in the temperature range between 200 and $300{ }^{\circ} \mathrm{C}$ [24].

The thermal decomposition step observed at higher temperatures $\left(400-600{ }^{\circ} \mathrm{C}\right.$, step 3 ) also showed the presence of water in the infrared spectra (Fig. 2c). We can suppose, in this case, that dehydroxylation takes place. Hydroxyl groups are bound to the clay structure by ionic or covalent bonds and are driven off by heating clay minerals to temperatures of $400{ }^{\circ} \mathrm{C}-700{ }^{\circ} \mathrm{C}$. The rate of loss of the hydroxyl groups and the energy required for their removal are specific properties characteristic of the various clay minerals [23, 27]. The mass losses assigned to the dehydroxylation phenomena for the samples analyzed in this work fall at relatively low temperatures (below $550{ }^{\circ} \mathrm{C}$ ). This has generally been regarded as an indication of high disorder [23, 27, 28]. Simultaneously with dehydroxylation, decarbonation also occurs, as highlighted by the presence of $\mathrm{CO}_{2}$ vibration bands in all the infrared spectra recorded in TG-FTIR experiments in the range $400-600{ }^{\circ} \mathrm{C}$. However, the temperature corresponding to the maximum of the evolution of $\mathrm{CO}_{2}$, practically matches the mass loss associated to step $4\left(600-800{ }^{\circ} \mathrm{C}\right)$. Thermal decomposition of $\mathrm{CaCO}_{3}$ into $\mathrm{CaO}$ and $\mathrm{CO}_{2}$ is widely documented to occur in this range [29].

\section{DSC measurements}

DSC was applied to investigate the heats of dehydration, by recording the heat flow in the temperature range from -40 to $300{ }^{\circ} \mathrm{C}$ of four samples considered as most representative of the different raw materials, and namely, UBS5 as a Numydian Flysch clay, PS8 and LCT10 as a PlioPleistocene clays, and Cianina as a marly clay (Figure S1). None of the samples examined shows endothermic signals at temperatures below $0{ }^{\circ} \mathrm{C}$ due to the melting of water. It has been widely demonstrated that melting and freezing of water inside the pores take place at temperatures significantly below zero [30], even dropping to $-50^{\circ} \mathrm{C}$ or even disappearing below a critical pore size $(3 \mathrm{~nm})$ [31]. The absence of DSC signals related to the melting can therefore indicate either that the temperature reached $\left(-40{ }^{\circ} \mathrm{C}\right)$ was not sufficient to cause the crystallization of the water or that the pools of bulk water are smaller than critical size [32]. Therefore, in all the samples examined, water is in the liquid state from $-40{ }^{\circ} \mathrm{C}$ to evaporation. The samples subjected to DSC analysis show, in the temperature range $50-200{ }^{\circ} \mathrm{C}$, an endothermic band with two peaks, quite well resolved in the case of USB5 and LCT10 (USB5: $T_{\text {peaks }}=72{ }^{\circ} \mathrm{C}, 133{ }^{\circ} \mathrm{C}$; LCT10: $T_{\text {peaks }}=67{ }^{\circ} \mathrm{C}, 128{ }^{\circ} \mathrm{C}$ ), and poorly resolved (the second peak being little more than a shoulder $)$ in the case of cyanine $\left(T_{\text {peaks }}=75^{\circ} \mathrm{C}\right.$, $\left.121^{\circ} \mathrm{C}\right)$. The DSC curve for PS 8 shows practically a single endothermic signal $\left(T_{\text {peak }}=75^{\circ} \mathrm{C}\right)$, with a barely hinted shoulder on the descent of the signal. Therefore, for PS8 and for Cianina, only an average value for the heat of dehydration was calculated, whereas in the other cases, we performed the deconvolution of the endothermic band and calculated a separated value for each peak. The values obtained were normalized per mole of water lost, according to the mass losses observed by TG by operating in high-resolution mode in the same range of temperature (High-ResTM TGA by Thermal Analysis). The heats of dehydration relative to the first endo peak (the only one in the case of PS 8 and Cianina) range from $56 \mathrm{~kJ} \mathrm{~mol}^{-1}$ for PS8 to $67 \mathrm{~kJ} \mathrm{~mol}^{-1}$ for USB5, (Cianina: $60 \mathrm{~kJ}$ mol-1; LCT10: $65 \mathrm{~kJ} \mathrm{~mol}^{-1}$ ). All these values are significantly higher than the evaporation enthalpy of water $\left(42 \mathrm{~kJ} \mathrm{~mol}^{-1}\right.$ at $70{ }^{\circ} \mathrm{C}$, i.e., at a temperature approximately corresponding to the peaks of the endo signals observed). This would suggest that low-temperature desorbed water, commonly referred to as loosely bound water, and surface water, or water trapped in the pores of the solid particle, is actually quite involved in bonding, probably with the $-\mathrm{OH}$ groups of the silicates.

Neither peak temperatures nor dehydration heats seem to indicate a differentiation based on the type and provenance of the samples for this endothermic signal. On the contrary, to the second endo peak corresponds enthalpic values of $39 \mathrm{~kJ} \mathrm{~mol}^{-1}$ and $79 \mathrm{~kJ} \mathrm{~mol}^{-1}$ for LCT10 and USB5, respectively. In the former, the value observed practically matches the enthalpy of vaporization of water at $130{ }^{\circ} \mathrm{C}$, whereas in the latter, the value is approximately double.

Although it is not easy to rationalize this behavior, it can be hypothesized that in the case of the Plio-Pleistocene clay sample (LCT10), the second water loss corresponds to a purely physical process in which the water molecules evaporate from host sites located in depth (among layers or in structural channels), but without being involved (or no longer at $130{ }^{\circ} \mathrm{C}$ ) in host-guest interactions. Instead, in the case of the Numidian Flysch sample (USB5), the second endo peak seems to be associated to the loss of water molecules rather strongly bound to the solid particles. 


\section{Statistical analysis}

Although it is possible to draw a general picture which allows us to roughly identify a common behavior, going in detail, the DTG curves of our samples showed very different profiles, with different degradation temperatures, different mass loss\% associated to each degradation step, including the lack of some of them, and therefore different thermal properties of the samples. The complexity of the data called for exploratory statistical methods. The thermogravimetric data obtained for each sample (the samples showing negligible mass losses were excluded from the statistical analysis) were submitted to multivariate classification procedures. Two approaches were parallelly followed: principal component analysis (PCA) and hierarchical clustering analysis (HCA) [33, 34]. Both methods have been extensively explored to classify archeological ceramics [33, 35-37] and in geological applications [38, 39]. The aim was to establish whether the overall set of thermal properties of the different samples analyzed could be used to define, among the raw materials, distinct groups potentially related to their chemi$\mathrm{cal} /$ mineralogical composition or geological and petrological origin and identify the most significant thermal features for their differentiation.

Both PCA and HCA were performed using as input variables the mass losses in the intervals identified from the TGA curves: $50-150{ }^{\circ} \mathrm{C}$ (step 1), 200-400 ${ }^{\circ} \mathrm{C}$ (step 2), 400-600 ${ }^{\circ} \mathrm{C}$ (step 3) and $600-800{ }^{\circ} \mathrm{C}$ (step 4) together with the residue at $900{ }^{\circ} \mathrm{C}$. PCA was performed using both the covariance and the correlation matrices. The latter procedure essentially corresponds to a normalization of each variable which is first translated by subtracting the mean value from each value, then scaled by dividing each translated value by the standard deviation. This approach allows to verify that excessive mass is not attributed to variables whose value is on average much larger and more dispersed than the other ones. The scatter plots and loading plots obtained by both approaches are shown in Fig. 3.

The loading plots (Fig. 3b and d) show that the first component (PC1) is largely dominated by the mass loss of step $4\left(600-800{ }^{\circ} \mathrm{C}\right.$, decarbonation) and by the residue. In the PCA obtained from the covariance matrix, in particular, these two quantities, whose contribution is comparable, cumulatively represent $99 \%$ of the variance of $\mathrm{PC} 1$, which alone represents $86.65 \%$ of the variance explained (total $98.46 \%)$. The second component (PC2) is instead dominated by the mass losses of steps $1\left(50-150{ }^{\circ} \mathrm{C}\right.$, dehydration) and $3\left(400-600{ }^{\circ} \mathrm{C}\right.$, mainly dehydroxylation), whose contribution is similar, while the contribution of the loss at $200-400{ }^{\circ} \mathrm{C}$ (step 2) is of little significance for both main components. However, while the mass loss contributions of steps 1 and 3 are directly correlated, the contribution of step 4 and the residue show an inverse correlation (Fig. S2 a, b).
In other words, samples with more significant mass losses at $50-150{ }^{\circ} \mathrm{C}$ tend to show more significant losses even at 400-600 ${ }^{\circ} \mathrm{C}$, while samples with greater mass losses in the $600-800{ }^{\circ} \mathrm{C}$ range tend to show a lower residue at $900{ }^{\circ} \mathrm{C}$. Wanting to simplify as much as possible, the PCA obtained from the covariance matrix indicates that only two input variables could be sufficient (one between the mass loss of step 4 and residual mass and one between the mass losses of steps 1 and 3) to allow a classification of the samples at least coarse.

The PCA obtained from the correlation matrix is only somewhat different. As can be seen from the corresponding loading plot (Fig. 3d), roughly, the overall effect of the data normalization is to have produced a rotation of $180^{\circ}$ around an axis nearly parallel to PC2 of the ellipsoid representing the data population. The result is that, in this case, the samples with high mass loss between 600 and $800{ }^{\circ} \mathrm{C}$ lie at negative $\mathrm{PC} 1$ values, as opposed to covariance matrix based PCA. In particular, the loading plot shows that the contribution of the different input variables to the two main components is less clearly separated. For example, even though the residual mass at $900{ }^{\circ} \mathrm{C}$ continues to contribute predominantly to $\mathrm{PC} 1$, the mass loss of step 4 contributes comparably to both principal components. Furthermore, the losses of steps 1 and 3 continue to contribute mainly to PC2, but with a non-negligible contribution to $\mathrm{PC} 1$, especially by step 1 . In this case, $\mathrm{PC} 1$ represents $42.55 \%$ of the variance explained, PC2 35.15\%.

Regardless of the differences observed in the two PCAs, both are able to separate the investigated samples based on their thermal properties, as shown by their respective score plots (Fig. 3a, c), suggesting that there is no significant bias as a consequence of the different variability of each parameter chosen for PCA.

In the score plot of the covariance matrix based PCA (Fig. 3 a), the samples are distributed on $\mathrm{PC} 1$ as a function of the mass loss in the range $600-800{ }^{\circ} \mathrm{C}$ and of the residue. In particular, the samples showing a greater loss of mass in the range $600-800{ }^{\circ} \mathrm{C}$ are placed at positive values of $\mathrm{PC} 1$ while those with a greater residue are placed at negative values. The separation of the sample on PC2, on the other hand, is mainly a function of the loss of mass in the range $400-600{ }^{\circ} \mathrm{C}$. The samples showing a higher value of this loss of mass are disposed to positive values of PC2 while those with lower mass loss are placed at negative values.

The PCA analysis highlights a samples separation by materials type. The Numydian Flysch clays are placed at negative values of $\mathrm{PC} 1$ and positive values of $\mathrm{PC} 2$, while the Plio-pleistocene clays at positive values of PC1 and prevailingly at values still positive of $\mathrm{PC} 2$, but on average lower than those of Numydian Flysch. Indeed, these two clay types mainly differ in mass loss at $600-800{ }^{\circ} \mathrm{C}$; in particular, the Plio-pleistocene clays present higher mass loss 
(a)

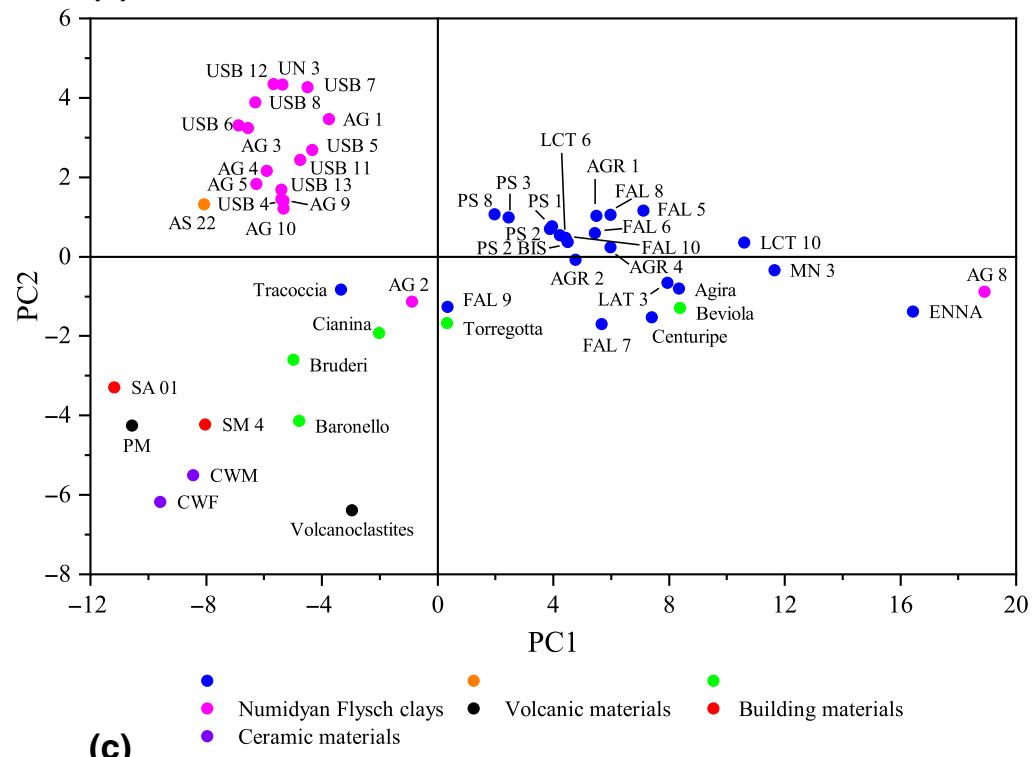

(c)

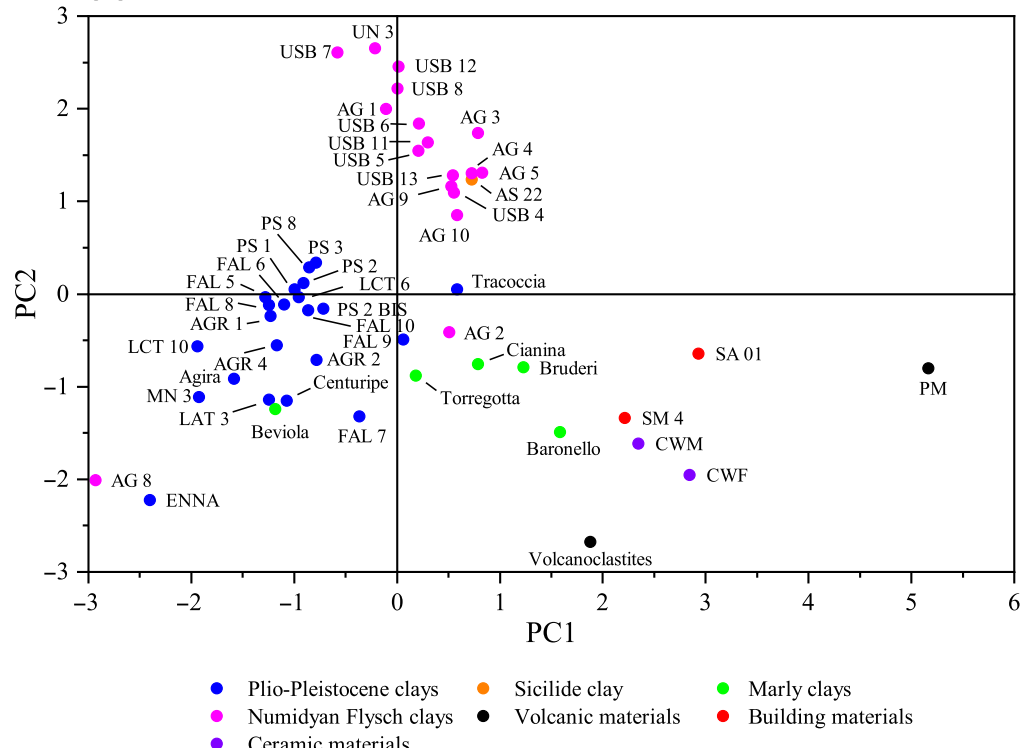

(b)

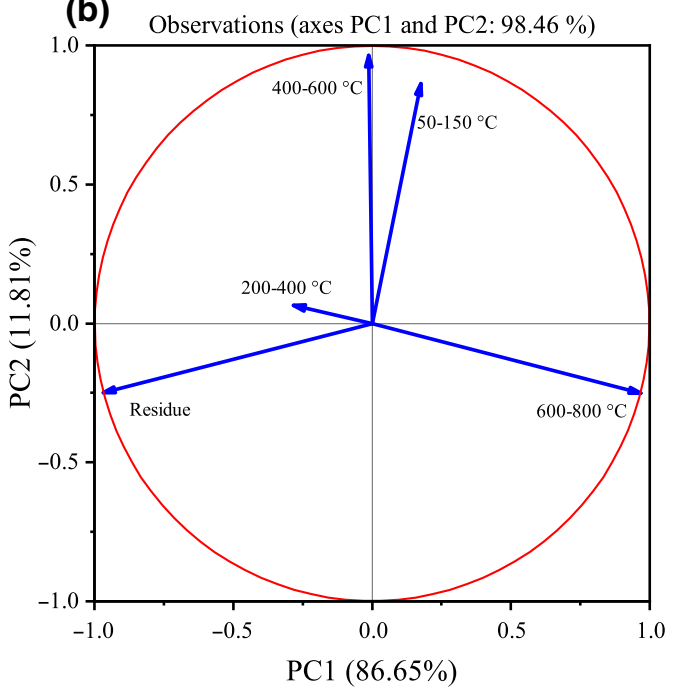

(d)

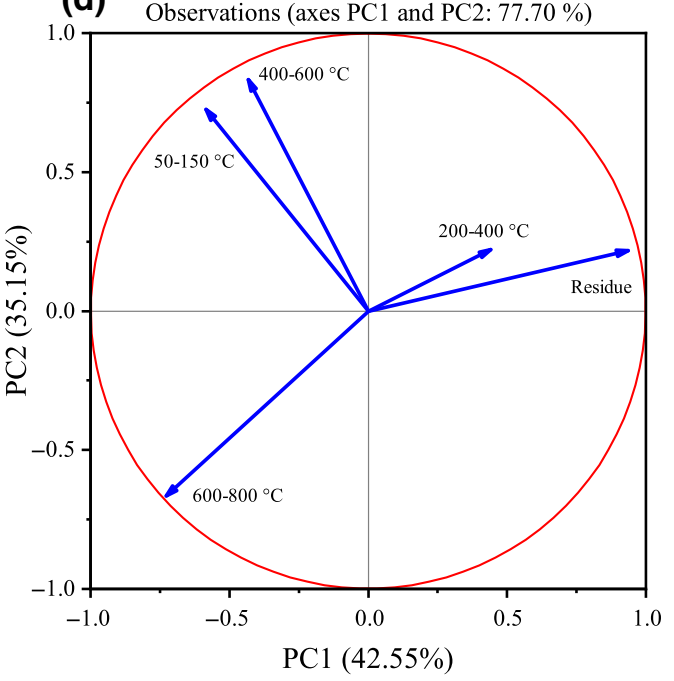

Fig. 3 Scatter plot (a and $\mathbf{c}$ ) and corresponding loadings plot (b and $\mathbf{d})$ obtained with covariance matrix (a and $\mathbf{b})$ and with correlation matrix (c and d)

than Numydian flysch clays. The marly clays are located at negative value of PC2 because present lower mass loss at $400-600^{\circ} \mathrm{C}$ than Numydian Flysch and Plio-pleistocene.

Building, ceramic and volcanic materials are located at negative values of $\mathrm{PC} 1$ in agreement with a high residue at $900{ }^{\circ} \mathrm{C}$ and a low, if not absent, mass loss at $50-150{ }^{\circ} \mathrm{C}$ and $400-600^{\circ} \mathrm{C}$ (Table S2, S3).

Similar considerations can be made also observing the correlation matrix based PCA, but with an approximately specular distribution of points (Fig. 3c).

Both score plots also evidence the formation of clusters including clays from different origin and sub-clusters with specific thermal characteristics. In particular, the scores plots indicate for the samples Tracoccia, Enna (Plio-pleistocene clays), Beviola (marly clay), and AG 8 (Numydian flysch) a thermal behavior which significantly differs from the other clays in the same category. These samples are outliers, being placed outside the clusters formed by most of the other clays of the same group.

Table 1 shows the $T_{\max }$, and mass loss percent mean values with the corresponding calculated relative standard deviations (RSD) for the clays analyzed in this work grouped by category and further divided into subgroups by geographic/ geological origin (see Table S1). The values corresponding 
Table $1 T_{\max }$, mean values, and calculated RSD for all the clays analyzed grouped by category and petrological origin. Type 1/Type 2 indicates the presence/absence of a mass loss in the temperature range of step 4

\begin{tabular}{|c|c|c|c|c|c|c|c|c|c|c|}
\hline & & & & \begin{tabular}{|l} 
Step 1 \\
$(50-150$
\end{tabular} & & $\begin{array}{l}\text { Step } 3 \\
(400-500\end{array}$ & & \begin{tabular}{|l|} 
Step 4 \\
$(600-800$
\end{tabular} & & \begin{tabular}{|l} 
Residue \\
$\left(900^{\circ} \mathrm{C}\right)$
\end{tabular} \\
\hline \multicolumn{2}{|l|}{ Category } & $\mathrm{n}$ & Value & $\begin{array}{c}\mathrm{T}_{\max /} \\
{ }^{\circ} \mathrm{C}\end{array}$ & $\begin{array}{c}\text { Mass loss } \\
\%\end{array}$ & $\begin{array}{c}\mathrm{T}_{\max /} \\
{ }^{\circ} \mathrm{C}\end{array}$ & $\begin{array}{c}\text { Mass loss } / \\
\%\end{array}$ & $\begin{array}{c}\mathrm{T}_{\max /} \\
{ }^{\circ} \mathrm{C}\end{array}$ & $\begin{array}{c}\text { Mass loss } \\
\%\end{array}$ & $\%$ \\
\hline \multirow[t]{12}{*}{$\begin{array}{l}\text { Plio-Pliocen } \\
\text { clays }\end{array}$} & \multirow[t]{2}{*}{ all } & \multirow{2}{*}{22} & Mean & 55 & 2.7 & 497 & 3.8 & 722 & 10.2 & 83.0 \\
\hline & & & RSD $\%$ & 7 & 20.9 & 1 & 19.1 & 2 & 29.4 & 3.3 \\
\hline & \multirow[t]{2}{*}{ PS } & \multirow{2}{*}{5} & Mean & 57 & 3.1 & 500.6 & 4.1 & 718 & 8.1 & 84.3 \\
\hline & & & RSD $\%$ & 9 & 7.6 & 0.4 & 9.3 & 3 & 9.9 & 0.9 \\
\hline & \multirow[t]{2}{*}{ FAL } & \multirow{2}{*}{6} & Mean & 55 & 2.6 & 494 & 3.7 & 712 & 9.6 & 83.6 \\
\hline & & & RSD $\%$ & 6 & 21.6 & 2 & 21.8 & 1 & 15.0 & 2.5 \\
\hline & \multirow[t]{2}{*}{ AGR } & \multirow{2}{*}{3} & Mean & 55 & 2.1 & 495 & 4.7 & 718 & 10.0 & 83.2 \\
\hline & & & RSD $\%$ & 6 & 15.6 & 1 & 6.2 & 2 & 4.4 & 0.7 \\
\hline & \multirow[t]{4}{*}{ LCT } & \multirow{2}{*}{3} & Mean & 56 & 2.8 & 498 & 3.7 & 734 & 11.5 & 81.6 \\
\hline & & & $\mathrm{RSD} \%$ & 4 & 28.7 & 1 & 5.4 & 2 & 20.9 & 2.7 \\
\hline & & \multirow{2}{*}{3} & Mean & 53 & 2.5 & 493 & 2.9 & 732 & 14.4 & 80.1 \\
\hline & & & RSD $\%$ & 4 & 29.1 & 1 & 19.2 & 2 & 25.3 & 4.3 \\
\hline \multirow{2}{*}{$\begin{array}{l}\text { Marly } \\
\text { clays }\end{array}$} & \multirow[t]{2}{*}{ all (Messina) } & \multirow{2}{*}{4} & Mean & 53 & 1.7 & 501 & 2.5 & 714 & 7.7 & 87.9 \\
\hline & & & RSD $\%$ & 6 & 36.3 & 1 & 30.1 & 4 & 44.8 & 5.2 \\
\hline \multirow[t]{18}{*}{$\begin{array}{l}\text { Numydia } \\
\text { n Flysch }\end{array}$} & \multirow[t]{2}{*}{$\mathrm{all}^{\mathrm{a}}$} & \multirow{2}{*}{17} & Mean & 61 & 3.2 & 504 & 5.3 & - & - & 88.6 \\
\hline & & & RSD $\%$ & 8 & 27.2 & 1 & 20.5 & - & - & 4.3 \\
\hline & \multirow[t]{2}{*}{ USB } & \multirow{2}{*}{8} & Mean & 62 & 3.5 & 505 & 5.7 & - & - & 89.4 \\
\hline & & & RSD $\%$ & 9 & 22.2 & 1 & 15.4 & - & - & 1.0 \\
\hline & \multirow[t]{2}{*}{$\mathrm{AG}$} & \multirow{2}{*}{8} & Mean & 60 & 2.7 & 504 & 4.8 & - & - & 87.7 \\
\hline & & & RSD $\%$ & 7 & 21.7 & 1 & 25.1 & - & - & 6.4 \\
\hline & \multirow[t]{2}{*}{ Type 1 all } & \multirow{2}{*}{12} & Mean & 60 & 3.1 & 505 & 4.8 & 691 & 3.4 & 88.1 \\
\hline & & & $\mathrm{RSD} \%$ & 7 & 27.1 & 1 & 18.3 & 6 & 160.5 & 5.1 \\
\hline & \multirow{2}{*}{ Type 1 USB } & \multirow{2}{*}{5} & Mean & 59 & 3.5 & 504 & 5.1 & 683 & 1.4 & 89.2 \\
\hline & & & $\mathrm{RSD} \%$ & 8 & 25.9 & 1 & 8.2 & 5 & 30.1 & 1.0 \\
\hline & Type 1 AG & 7 & Mean & 60 & 2.7 & 505 & 4.6 & 697 & 4.8 & 87.3 \\
\hline & & t & RSD $\%$ & 7 & 22.3 & 1 & 23.6 & 7 & 146.1 & 6.8 \\
\hline & Type 2 all & 5 & Mean & 62 & 3.4 & 503 & 6.4 & - & - & 89.6 \\
\hline & & 5 & RSD $\%$ & 10 & 28.7 & 1 & 7.4 & - & - & 1.0 \\
\hline & Type 2 USB & 3 & Mean & 67 & 3.3 & 506 & 6.7 & - & - & 89.8 \\
\hline & & & RSD $\%$ & 6 & 16.9 & 1 & 2.3 & - & - & 0.9 \\
\hline & Type 2 AG ${ }^{b}$ & 1 & Mean & 57 & 2.3 & 495 & 6.5 & - & - & 90.1 \\
\hline & & 1 & RSD $\%$ & - & - & - & - & - & - & - \\
\hline
\end{tabular}

The first line of each category (all) is related to all the clays in the category, while the values below correspond to subgroups of the same petrological/geological origin

${ }^{a}$ Since not all the samples pertaining to the Numydian Flysch category show a mass loss in the range of step 4, the mean values were not calculated on the aggregate data

${ }^{\mathrm{b}}$ In the AG group, there is only one sample (AG 3) belonging to Type 2 subgroup; therefore, no RSD\% value is reported

to step $2\left(200-400{ }^{\circ} \mathrm{C}\right)$ have not been reported as not all clays show a mass loss in this range and, in any case, it is always between 0.4 and $1 \%$. The flag Type 1/Type 2 corresponds to the presence/absence of a mass loss in the range of step 4 . The first line of each category (all) is related to all the pertaining clays, while the values below correspond to the clays of each subgroups. RSD is indicative of the dispersion of the values with respect to the average value calculated within each category/subgroup. While the $T_{\max }$ values show in all cases a low intra-group variability (RSD less than $10 \%$ ), the mass losses systematically show an RSD greater than $20 \%$. This indicates that although the chemical phenomena underlying the observed mass losses and the chemical environment in which they occur are substantially the same, the extent of the phenomena can be significantly different even between clays belonging to the same category.

Decarbonation step $\left(600-800{ }^{\circ} \mathrm{C}\right)$ is present in $80 \%$ of the clays (including all the Plio-pleistocene clays, Marly clays, and half of the Numydian Flysch clays), while it is not present in $20 \%$ of them, including the Sicilide clay and 
the other half of the Numydian Flysch clays. Actually, the type 1 Numidian Flysch shows a decarbonation mass loss much lower than all the other clays here examined (mean value $\approx 2 \%$ ), and, correspondingly, higher residue at $900{ }^{\circ} \mathrm{C}$. Accordingly, the Numydian Flysch cluster (C1) is located at negative values of $\mathrm{PC} 1$ (between -3 and -8 ) but at positive values of PC2 in covariance matrix based PCA, with the Type 2 grouped in the upper part. There is no distinction within the Numydian Flysch cluster related to the petrological/geological origin (see Table S1). To the same cluster of Numydian Flysch belongs also the Sicilide clay (AS22).

Plio-pleistocene clays, showing on average a mass loss related to decarbonation of $10 \%$, are mainly located at positive values of PC1 (between 2 and 8 ) and between 0 and 2 values of PC2 in covariance matrix based PCA being mainly clustered together $(\mathrm{C} 2)$. The dispersion along PC1 axis reflects the RSD value for the mass loss of step 4 which is as high as $30 \%$. However, the PCA allows to highlight the presence, within $\mathrm{C} 2$, of two sub-clusters related to the petrological origin of the samples, the first formed by Poggio Safanello clays, PS, (at low PC1 values) and the second constituted by most of Falconara, FAL, and Agrigento, AGR, clays. Another cluster (C3) including FAL 7, LAT 3, Agira, Centuripe, MN 3, LCT 10 lies approximately in the same range of $\mathrm{PC} 1$ values, but at negative values of $\mathrm{PC} 2$. In the same region of PCA falls also the Beviola sample, a Marly clay which exhibits a mass loss $>10 \%$ at $741{ }^{\circ} \mathrm{C}$.

Marly clays are spread over a wide range of PC1 values either positive or negative, and at negative values of PC2, mainly due to their relatively low water content. This spread reflects the high values of RSD calculated for the mass losses of this category. In particular, degradation step 4, with a mass loss ranging from 5\% (Baronello) to $13 \%$ (Beviola), shows an RSD of 45\%, significantly higher than the other clays. A cluster (C4), including most of Marly clays, can be identified at $\mathrm{PC} 1$ values ranging from -5 to 1 and $\mathrm{PC} 2$ from -5 to 0 . A small cluster (C5) located at PC1 values above 15 and slightly negative $\mathrm{PC} 2$ values includes the two outliers AG 8 and ENNA.

A last cluster (C6) including the building raw materials is located at negative values of both PC1 (from -8 to -12 ) and PC2 $(-3$ to -6$)$. In fact, despite showing a significant mass loss in the range of step 4 , these materials show a high residue at $900{ }^{\circ} \mathrm{C}$ due to very low mass losses in other steps (1-3).

The calculated average mass losses for the different clusters (except for C6 including materials with a single mass loss) are reported in Table S4. The average thermal profiles (accounting for mass losses related to steps 1, 3 and 4) of the clays investigated, grouped by cluster and by category are plotted in Fig. S4 a and b, respectively. The results evidence that the main difference is given by the mass loss in the range $600-800{ }^{\circ} \mathrm{C}$ for both grouping. Thermal profiles in fact appear as isosceles triangles whose vertical axis of symmetry is the mass loss around $700{ }^{\circ} \mathrm{C}$. However, the cluster $\mathrm{C} 1$, including all the Numidian Flysch samples, shows a different profile respect to others. These clays are characterized by a high mass loss around $500{ }^{\circ} \mathrm{C}$ (step 3 ) and a low mass loss at $700{ }^{\circ} \mathrm{C}$ generating a thermal profile appearing as a scalene triangle, particularly for samples with no mass loss at $700{ }^{\circ} \mathrm{C}$ (Type 2) as shown in Fig. S4 b.

As a summary consideration, it can be stated that the investigated clays can be classified based on the ratio between water loss and decarbonation.

To further investigate the clusters formed by the clay samples and the relation among them, HCA was applied to the thermogravimetric data of clay samples only ( 45 samples). The cluster trees, or dendrograms, obtained are shown in Fig. S3. The cluster tree defines various levels of classification based on its hierarchic branches. Similar objects are placed on one branch (cluster) and each branch represents a separated group. Consequently, clusters at one level of correlation are joined at the next higher level and the height of each branching point is proportional to the distance between the two objects being connected [33]. HCA cluster tree obtained by considering Euclidean distances and using average linkage (UPGMA) as clustering method is plotted in Figure S3. The cluster tree reproduces virtually the same groupings observed in the PCA analysis. Interestingly, using different linkage methods such as weighted average linkage (WPGMA) or the Ward's method, the dendrograms obtained show similar results grouping the samples in the same main clades formed by clay samples of the same category. The dendrograms differ only in the level of distance of the links between the clades and in the positioning of some clays, already identified as outliers in the PCA analysis.

\section{XRD and gasometry}

In order to link the thermal properties of the samples to their chemical/mineralogical composition, XRD and gasometry were applied on selected samples representatives of the different clusters in the PCA and HCA and of the thermal behaviors observed. The mineralogical composition of the samples resulting from the XRD analysis is reported in Table S5, and the corresponding XRD patterns are showed in Figure S5.

XRD patterns showed that in all the sample quartz phases and calcite were present. Plio-Pleistocene clays (FAL5, FAL9, AGR2), Marly clays (Cianina and Beviola) and two of the Numidian Flysch clays (AG 3 and AG 8 ) showed the presence of feldspars. Marly clay samples as well as the Sicilide clay (AS22) also showed the presence of mica phases in their composition. All the XRD pattern of the samples well fit with local deposits of Sicilian clay 
$[40,41]$ except for the LBCa sample that is a building waste material.

The presence of calcite is related to the decarbonation phenomena evidenced by the presence of the characteristic $\mathrm{CO}_{2}$ vibrational bands in the FTIR spectra of the evolved gas in the range $400-800{ }^{\circ} \mathrm{C}$ (Fig. 2). Water from dihydroxylation was also present on the spectra. In order to quantitatively evaluate the amount of water of this kind as well as the carbonate content of the samples, TG results were used in combination with calcimetry measurements [21]. The water from dehydroxylation contained by the different clays, estimated as the difference between the overall mass loss above $150{ }^{\circ} \mathrm{C}$ and the $\mathrm{CO}_{2}$ measured by calcimetry, is reported in Table 2.

From the results is evidenced that the amount of $\mathrm{CO}_{2}$ detected by calcimetry is very similar to the mass loss in the range $600-800{ }^{\circ} \mathrm{C}$, confirming that decarbonation occurs mainly during step 4 as highlighted by the evolution of $\mathrm{CO}_{2}$ observed in TG-FTIR experiments (Fig. 2). Samples showing a $\mathrm{CO}_{2}$ content below $1 \%$ are the same that do not show any mass loss in the range $600-800{ }^{\circ} \mathrm{C}$. However, these samples showed the presence of calcite in the diffraction patterns (Fig. S5). These results highlight the complementarity of the approach followed in the characterization of raw materials.

By plotting the amount of structural water versus the percentual of $\mathrm{CO}_{2}$ (Fig. 4 a), it can be easily noticed that samples are grouped as in the PCA (Fig. 3). The amount of structural water allows to distinguish samples AG 3 and USB 11 with a structural amount of water around 6-7\% and the rest of the samples showing a content between 3 and $4 \%$. The amount of $\mathrm{CO}_{2}$ allows to separate the samples in groups as follows: samples AS 22, AG 3 and USB 11 with a $\mathrm{CO}_{2}$ content below $5 \%$, samples Cianina and FAL $9\left(\mathrm{CO}_{2}\right.$ between 5 and 10\%), FAL5, AGR 2 and Beviola $\left(\mathrm{CO}_{2}\right.$ between 10 and $\left.15 \%\right)$ and sample AG 8 (around $20 \%)$. (a)

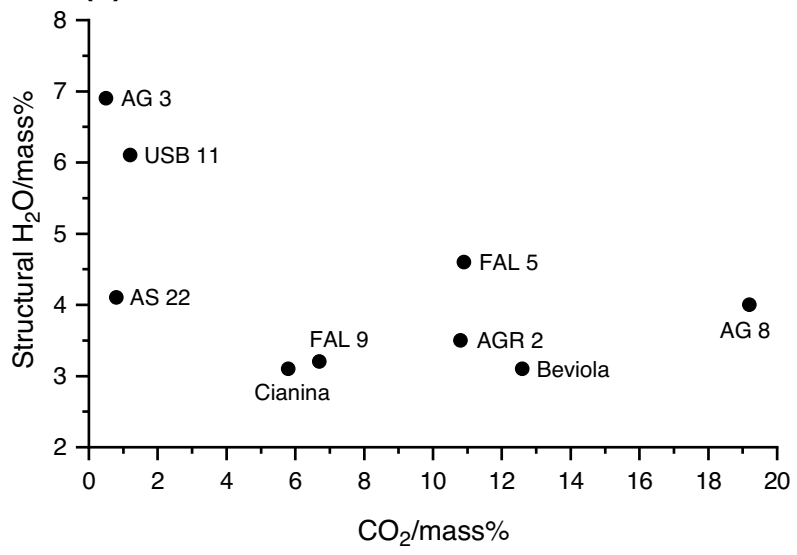

(b)

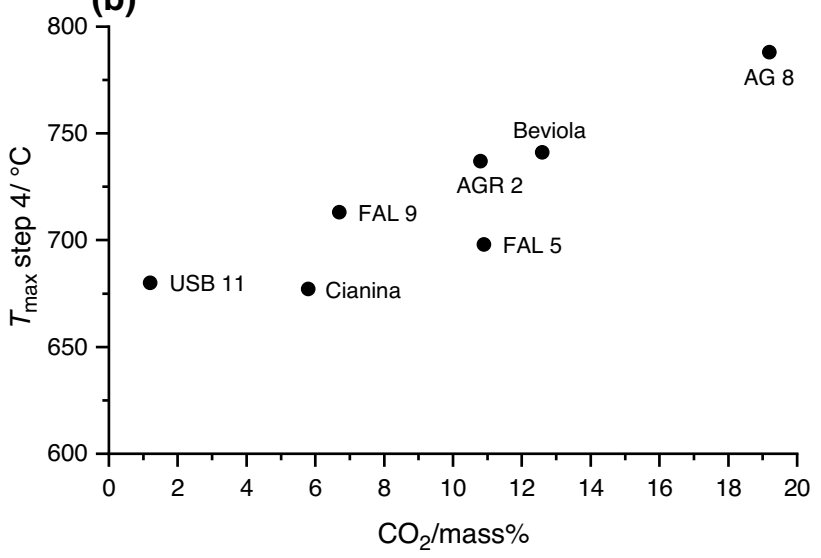

Fig. 4 Dispersion graph representing the a \% of structural water (as calculated in Table 2) and $\mathbf{b} T_{\max }$ of step 4 (decarbonation) versus \% of $\mathrm{CO}_{2}$ from calcimetry

All these results highlight that the amount of carbonate, calcite on the basis of the XRD patterns obtained, is the main feature classifying the clays. The amount of calcite calculated from the $\%$ of $\mathrm{CO}_{2}$ is inversely related to the residue at $900{ }^{\circ} \mathrm{C}$. The combination of thermogravimetric and

Table 2 Results from the characterization of the samples in terms of water content from TGA and $\mathrm{CO}_{2}$ from calcimetry

\begin{tabular}{|c|c|c|c|c|c|c|c|}
\hline Sample name & $\begin{array}{l}\text { Loosely bound } \\
\text { water } \mathrm{H}_{2} \mathrm{O} \text { (step 1) }\end{array}$ & $\begin{array}{l}\text { Mass loss } 200- \\
400{ }^{\circ} \mathrm{C} \text { (step 2) }\end{array}$ & $\begin{array}{l}\text { Mass loss } 400- \\
600^{\circ} \mathrm{C}(\text { step } 3)\end{array}$ & $\begin{array}{l}\text { Mass loss 600- } \\
800^{\circ} \mathrm{C} \text { (step 4) }\end{array}$ & (steps $2,3,4)$ & $\mathrm{CO}_{2}$ & $\mathrm{H}_{2} \mathrm{O}$ structural \\
\hline FAL 5 & 3.1 & 0.8 & 4.2 & 10.5 & 15.5 & 10.9 & 4.6 \\
\hline FAL 9 & 2.6 & 0.3 & 2.6 & 7.0 & 9.9 & 6.7 & 3.2 \\
\hline AGR2 & 1.7 & - & 4.5 & 9.8 & 14.3 & 10.8 & 3.5 \\
\hline AG 3 & 2.3 & 0.9 & 6.5 & - & 7.4 & $<0.5$ & $>6.9$ \\
\hline AG 8 & 2.5 & 0.3 & 3.2 & 20.0 & 23.5 & 19.2 & 4.0 \\
\hline USB 11 & 3.6 & 0.9 & 4.9 & 1.5 & 7.3 & 1.2 & 6.1 \\
\hline Cianina & 1.6 & 0.3 & 2.8 & 5.8 & 8.9 & 5.8 & 3.1 \\
\hline Beviola & 2.5 & 0.3 & 2.7 & 12.7 & 15.7 & 12.6 & 3.1 \\
\hline AS22 & 2.8 & - & 4.9 & - & 4.9 & 0.8 & 4.1 \\
\hline
\end{tabular}


gasometric measurements confirmed a direct correlation between surface and structural water, coherently with what has already been highlighted in Fig. S2 a.

Moreover, the $T_{\max }$ of the decarbonation step is approximately linearly related to $\mathrm{CO}_{2}$ content, the lower $\mathrm{CO}_{2} \%$, that is the calcite content, the lower the $T_{\max }$ (Fig. $4 \mathrm{~b}$ ). It is noteworthy that the $T_{\max }$ for step 4 of sample AG 8 is higher than that of sample ENNA $\left(749^{\circ} \mathrm{C}\right)$ though the amount of calcite is around $20 \%$ for both. This could indicate a higher order in the crystalline structure of calcite $[42,43]$. However, it has been reported that the presence of silicates and impurities can accelerate decarbonation, and therefore decrease the temperature at which the phenomenon occurs [44].

\section{Conclusions}

Different materials showed different thermal behavior. The multi-analytical approach used allowed to establish that the key factors for the classification are the content of calcite and structural water in the clay.

Results show that Plio-pleistocene clays as well as Numidian Flysch show very similar thermal behavior intragroup. Numidian Flysch clays are characterized by a high residue (90\%) and low mass loss at $700{ }^{\circ} \mathrm{C}(0$ to $2 \%)$ indicating a low amount of calcite in their composition, while Pliopleistocene clays show a lower residue $(80 \%)$ and a higher loss at $700{ }^{\circ} \mathrm{C}$ and are therefore characterized by higher amount of carbonate. Numidian Flysch clays are characterized by a higher amount of structural water respect to the rest of clays. However, data also evidenced that some samples from each type of clays showed particular thermal features, mainly related to a higher amount of calcite, that do not allow the clustering with the other clays of the same category.

Data highlighted that $T_{\max }$ for the different clays is very similar showing RSD below $10 \%$ for the different degradation steps observed. The highest variability is encountered for step 1 as is linked to the superficial water and depends partly on the sample porosity and for step 4 . The variability of the latter is, however, related to the amount of water and to the crystallinity of the calcite.

In the context of geopolymer production, the information regarding thermal behavior of raw materials assumes a key point since, especially for clay sediments, it is a common practice the thermal treatments with the aim to enhance their rection with alkaline solutions. Furthermore, other important information concerns calcite decarbonation and lime production that contribute to the mineralogical composition and the mechanical resistance of geopolymers.
Supplementary Information The online version contains supplementary material available at https://doi.org/10.1007/s10973-021-11077-7.

Acknowledgements This research is supported by the Advanced Green Materials for Cultural Heritage (AGM for $\mathrm{CuHe}$ ) project (PNR fund with code: ARS01_00697; CUP E66C18000380005). The authors are grateful to Dr. Giuseppe Sabatino of University of Messina for supplying some of the investigated samples.

Funding Open access funding provided by Università di Pisa within the CRUI-CARE Agreement. This research is supported by the Advanced Green Materials for Cultural Heritage (AGM for $\mathrm{CuHe}$ ) project (PNR fund with code: ARS01_00697; CUP E66C18000380005).

Data availability Raw data will be made available upon request.

\section{Declarations}

Conflict of interests The authors declare no conflicts of interests.

Open Access This article is licensed under a Creative Commons Attribution 4.0 International License, which permits use, sharing, adaptation, distribution and reproduction in any medium or format, as long as you give appropriate credit to the original author(s) and the source, provide a link to the Creative Commons licence, and indicate if changes were made. The images or other third party material in this article are included in the article's Creative Commons licence, unless indicated otherwise in a credit line to the material. If material is not included in the article's Creative Commons licence and your intended use is not permitted by statutory regulation or exceeds the permitted use, you will need to obtain permission directly from the copyright holder. To view a copy of this licence, visit http://creativecommons.org/licenses/by/4.0/.

\section{References}

1. Ng C, Alengaram UJ, Wong LS, Mo KH, Jumaat MZ, Ramesh S. A review on microstructural study and compressive strength of geopolymer mortar, paste and concrete. Constr Build Mater. 2018. https://doi.org/10.1016/j.conbuildmat.2018.07.075.

2. Occhipinti R, Stroscio A, Finocchiaro C, Fugazzotto M, Leonelli C, Lo Faro MJ, Bartolomeo M, Barone G, Mazzoleni P. Alkali activated materials using pumice from the Aeolian Islands (Sicily, Italy) and their potentiality for cultural heritage applications: preliminary study. Constr Build Mater. 2020. https://doi.org/10. 1016/j.conbuildmat.2020.120391.

3. Pagnotta $\mathrm{S}$, Tenorio AL, Tinè MR, Lezzerini M. Geopolymer mortar: Metakaolin-based recipe for cultural heritage application. In 2020 IMEKO TC-4 international conference on metrology for archaeology and cultural heritage; 2020. p. 55-9.

4. Pagnotta S, Tenorio AL, Tinè MR, Lezzerini M. Geopolymers as a potential material for preservation and restoration of Urban Build Heritage: an overview. In IOP conference series: earth and environmental science. 2020;609:012057. https://iopscience.iop. org/article/https://doi.org/10.1088/1755-1315/609/1/012057

5. Finocchiaro C, Barone G, Mazzoleni P, Sgarlata C, Lancellotti I, Leonelli C, Romagnoli M. Artificial neural networks test for the prediction of chemical stability of pyroclastic depositsbased AAMs and comparison with conventional mathematical approach (MLR). J Mater Sci. 2021. https://doi.org/10.1007/ s10853-020-05250-w. 
6. Finocchiaro C, Barone G, Mazzoleni P, Leonelli C, Gharzouni A, Rossignol S. FT-IR study of early stages of alkali activated materials based on pyroclastic deposits (Mt. Etna, Sicily, Italy) using two different alkaline solutions. Constr Build Mater. 2020. https://doi.org/10.1016/j.conbuildmat.2020.120095.

7. Barone G, Finocchiaro C, Lancellotti I, Leonelli C, Mazzoleni $\mathrm{P}$, Sgarlata C, Stroscio A. Potentiality of the use of pyroclastic volcanic residues in the production of alkali activated material. Waste Biomass Valoriz. 2021. https://doi.org/10.1007/ s12649-020-01004-6.

8. Geraldes CFM, Lima AM, Delgado-Rodrigues J, Mimoso JM, Pereira SRM. Geopolymers as potential repair material in tiles conservation. Appl Phys A. 2016. https://doi.org/10.1007/ s00339-016-9709-3.

9. S. Tamburini, M. Favaro, A. Magro, E. Garbin, M. Panizza, F. Nardon, M.R. Valluzzi, Geopolymers as strengthening materials for Built Heritage. In Boriani M et al. editor. Proceedings of built heritage 2013 - monitoring conservation management. Milan (IT); 2013. p. 18-20: 1304-1311

10. Elert K, Sebastián E, Valverde I, Rodriguez-Navarro C. Alkaline treatment of clay minerals from the Alhambra Formation: implications for the conservation of earthen architecture. Appl Clay Sci. 2008. https://doi.org/10.1016/j.clay.2007.05.003.

11. Rescic S, Plescia P, Cossari P, Tempesta E, Capitani D, Proietti N, Fratini F, Mecchi AM. Mechano-chemical activation: an ecological safety process in the production of materials to stone conservation. Procedia Eng. 2011. https://doi.org/10.1016/j.proeng.2011. 11.2112.

12. Clausi M, Tarantino SC, Magnani LL, Riccardi MP, Tedeschi C, Zema M. Metakaolin as a precursor of materials for applications in cultural heritage: geopolymer-based mortars with ornamental stone aggregates. Appl Clay Sci. 2016;132-133:589-99.

13. Catauro M, Dal Poggetto G, Sgarlata C, VecchioCiprioti S, Pacifico S, Leonelli C. Thermal and microbiological performance of metakaolin-based geopolymers cement with waste glass. Appl Clay Sci. 2020. https://doi.org/10.1016/j.clay.2020.105763.

14. Ricciotti L, Jacopo Molino A, Roviello V, Chianese E, Cennamo P, Roviello G. Geopolymer composites for potential applications in cultural heritage. Environments. 2017. https://doi.org/10.3390/ environments4040091.

15. Tamburini S, Natali M, Garbin E, Panizza M, Favaro M, Valluzzi MR. Geopolymer matrix for fibre reinforced composites aimed at strengthening masonry structures. Constr Build Mater. 2017. https://doi.org/10.1016/j.conbuildmat.2017.03.017.

16. Wu Y, Lu B, Yi Z, Du F, Zhang Y. The properties and latest application of geopolymers. In IOP conference series: materials science and engineering. 2019. https://doi.org/10.1088/1757-899X/472/1/ 012029

17. Aguirre-Guerrero AM, Robayo-Salazar RA, de Gutiérrez RM. A novel geopolymer application: coatings to protect reinforced concrete against corrosion. Appl Clay Sci. 2017. https://doi.org/ 10.1016/j.clay.2016.10.029.

18. Hanzlíček T, Steinerová M, Straka P, Perná I, Siegl P, Švarcová T. Reinforcement of the terracotta sculpture by geopolymer composite. Mater Des. 2009. https://doi.org/10.1016/j.matdes.2008. 12.015 .

19. Smykatz-Kloss W, Heide K, Klinke W. Applications of thermal methods in the geosciences. In: Brown ME, Gallagher PK, editors. Handbook of thermal analysis and calorimetry. Amsterdam: Elsevier; 2003. pp. 451-593.

20. Bergaya F, Lagaly G. Handbook of clay science. 2nd ed. Amsterdam: Elsevier; 2013.

21. Leone G, Leoni L, Sartori F. Revisione di un metodo gasometrico per la determinazione di calcite e dolomite. Atti Soc Tosc Sci Nat Mem A. 1988;95:7-20.
22. Demšar J, Curk T, Erjavec A, Gorup Č, Hočevar T, Milutinovič $\mathrm{M}$, et al. Orange: Data mining toolbox in python. J Mach Learn Res. 2013;14:2349-53.

23. Rouquerol F, Rouquerol J, Llewellyn P. Thermal Analysis. In developments in clay science. Amsterdam: Elsevier; 2013. Pp. 361-79.

24. Földvári M. Handbook of thermogravimetric system of minerals and its use in geological practice. Budapest: Geological Institute of Hungary Budapest; 2011.

25. Brown M, Gallagher P. Handbook of thermal analysis and calorimetry. 1st ed. Amsterdam: Elsevier Science; 2003.

26. Mackenzie RC. The montmorillonite differential thermal curve. I. - General variability in the dehydroxylation region. Bulletin du Groupe français des argiles. PERSEE Program. 1957; 9: 7-15.

27. Smykatz-Kloss W, Heide K, Klinke W. Applications of thermal methods in the geosciences. In: Brown ME, Gallagher PK, editors. Handbook of thermal analysis and calorimetry. Amsterdam: Elsevier B.V.; 2003. pp. 451-593.

28. Meyers KS, Speyer RF. Thermal analysis of clays. In: Brown ME, Gallagher PK, editors. Handbook of thermal analysis and calorimetry. Amsterdam: Elsevier B.V.; 2003. pp. 261-306.

29. Legens C, Palermo T, Toulhoat H, Fafet A, Koutsoukos P. Carbonate rock wettability changes induced by organic compound adsorption. J Pet Sci Eng. 1998;20:277-82.

30. Sliwinska-Bartkowiak M, Jazdzewska M, Huang LL, Gubbins KE. Melting behavior of water in cylindrical pores: carbon nanotubes and silica glasses. Phys Chem Chem Phys. 2008. https://doi.org/ 10.1039/B808246D.

31. Jähnert S, Vaca Chávez F, Schaumann GE, Schreiber A, Schönhoff $\mathrm{M}$, Findenegg GH. Melting and freezing of water in cylindrical silica nanopores. Phys Chem Chem Phys. 2008. https://doi.org/ 10.1039/B809438C.

32. Liu J, Nicholson CE, Cooper SJ. Direct measurement of critical nucleus size in confined volumes. Langmuir. 2007. https://doi.org/ 10.1021/la063650a.

33. Baxter MJ, Buck CE. Data handling and statistical analysis. Modern analytical methods in art and archaeology. Wiley; 2000. pp. 681-746.

34. Jolliffe IT, Cadima J. Principal component analysis: a review and recent developments. Philos Trans A Math Phys Eng Sci. 2016. https://doi.org/10.1098/rsta.2015.0202.

35. Cariati F, Fermo P, Gilardoni S, Galli A, Milazzo M. A new approach for archaeological ceramics analysis using total reflection X-ray fluorescence spectrometry. Spectrochim acta part $\mathrm{b}$ at spectrosc. 2003;58:177-84.

36. Karasik A, Smilansky U. Computerized morphological classification of ceramics. J Archaeol Sci. 2011. https://doi.org/10.1016/j. jas.2011.05.023.

37. Papageorgiou I, Liritzis I. Multivariate mixture of normals with unknown number of components: an application to cluster Neolithic ceramics from Aegean and Asia minor using portable XRF. Archaeometry. 2007;49:795-813.

38. Walter J, Chesnaux R, Cloutier V, Gaboury D. The influence of water/rock-water/clay interactions and mixing in the salinization processes of groundwater. J Hydrol Reg Stud. 2017. https://doi. org/10.1016/j.ejrh.2017.07.004.

39. Martelet G, Truffert C, Tourlière B, Ledru P, Perrin J. Classifying airborne radiometry data with agglomerative hierarchical clustering: a tool for geological mapping in context of rainforest (French Guiana). Int J Appl Earth Obs Geoinf. 2006. https://doi.org/10. 1016/j.jag.2005.09.003.

40. Montana G, Cau Ontiveros MÁ, Polito AM, Azzaro E. Characterisation of clayey raw materials for ceramic manufacture in ancient Sicily. Appl Clay Sci. 2011. https://doi.org/10.1016/j.clay.2010. 09.005. 
41. Barbera G, Lo Giudice A, Mazzoleni P, Pappalardo A. Combined statistical and petrological analysis of provenance and diagenetic history of mudrocks: application to Alpine Tethydes shales (Sicily, Italy). Sediment Geol. 2009. https://doi.org/10.1016/j.sedgeo. 2008.11.002.

42. Criado JM, Ortega A. A study of the influence of particle size on the thermal decomposition of $\mathrm{CaCO} 3$ by means of constant rate thermal analysis. Thermochim Acta. 1992. https://doi.org/ 10.1016/0040-6031(92)80059-6.

43. Gunasekaran S, Anbalagan G. Thermal decomposition of natural dolomite. Bull Mater Sci. 2007;30:339-44.
44. Tunney J, Detellier C. Preparation and characterization of an 8.4 $\AA$ A hydrate of kaolinite. Clays Clay Miner. 1994;42:473-6.

Publisher's Note Springer Nature remains neutral with regard to jurisdictional claims in published maps and institutional affiliations. 